\title{
Sistem Informasi Inventory Berbasis Website (Studi Kasus : Pada Toko Obyth)
}

\author{
Kristin Mamit Thalia $^{1),}$ Enny Dwi Oktaviyani2 ${ }^{2 *}$, Felicia Sylviana ${ }^{3}$ \\ 1)2)3) Jurusan Teknik Informatika, Fakultas Teknik, Universitas Palangka Raya \\ Jalan Hendrik Timang Kampus UPR Tunjung Nyaho, Palangka Raya \\ *corresponding author \\ 1) kristinmamitthalia@gmail.com \\ 2) enny.obrien@gmail.com \\ 3) felicia.upr@gmail.com
}

\begin{abstract}
Abstrak
Data inventory pada Toko Obyth masih dubuat dalam buku agenda besar, sehingga pemilik toko dan kasir kesulitan saat melihat informasi data inventory barang yang ada.Maka dari itu dibutuhkan suatu sistem informasi ini persediaan barang dengan menggunakan metode Reorder point. Metode ini membantu pemilik toko untuk mengecek persediaan jumlah barang tanpa harus pergi kegudang terlebih dahulu, dan menghindari dari kehabisan stock jumlah persediaan barang dan pemilik toko dapat mengetahui titik waktu kapan harus dilakukannya pemesanan kembali.

Sistem ini menggunakan 2 metode yaitu waterfall sebagai metode pengembangan perangkat lunak dan metode Re Order Point sebagai metode dalam sistem informasi inventory yang dibuat. Re order point memiliki 3 faktor untuk mendapatkan hasil dari re order point nya, yaitu lead time, average usage, dan safety stock .Berdasarkan tahapan metode waterfall ada beberapan tahapan yaitu requirement definition, system and software design, implemetation and unit testing, integration and system testing dan operation. Perangkat lunak yang digunakan dalam membangun website ini adalah Sublime, MySQL, dan XAMPP.

Website ini telah diuji dengan pengujian blackbox yang menghasilkan bahwa fitur dalam website dapat berjalan dengan baik. Sistem Informasi Inventory Berbasis Website (Studi Kasus : Pada Toko Obyth) ini dibangun untuk memberikan informasi persediaan (Inventory) barang yang disimpan untuk dijual.
\end{abstract}

Kata kunci: inventory, Toko Obyth, Reorder point, waterfall

\begin{abstract}
Inventory data on Obyth Store is still made in the big agenda book, so store owners and cashiers have difficulty when viewing the inventory data information of existing goods. Therefore, it takes a system of information on inventory of goods using the Reorder point method. This method helps the shop owner to check the inventory quantity of goods without having to go around first, and avoid running out of stock the amount of inventory and the store owner can know the point of time when to rebook.

This system uses 2 methods namely waterfall as a software development method and Re Order Point method as a method in the inventory information system created. Re order point has 3 factors to get the result of its re order point, namely lead time, average usage, and safety stock. Based on the waterfall method stage there are several stages namely requirement definition, system and software design, implemetation and unit testing, integration and system testing and operation. The software used in building this website is Sublime, MySQL, and $X A M P P$.
\end{abstract}


This website has been tested with blackbox testing which results in that the features in the website can run well. Website-Based Inventory Information System (Case Study: In Obyth Store) is built to provide inventory information of goods stored for sale.

\section{Keywords : Inventory, Toko Obyth, Reoreder Point, Waterfall}

\section{PENDAHULUAN}

Keberadaan barang persediaan (inventory) dalam aktivitas kehidupan manusia tidak dapat dihindari baik dalam kegiatan pribadi, rumah tangga, sosial, kantor maupun usaha. Yang membedakan diantaranya dalah jenis dan jumlah barang, karakteristik kebutuhan barang dan intensitas pengelolaannya. Keberadaan inventory sanagt diperlukan untuk menjamin kelancaraan pemenuhan permintaan sebab bila tidak ada inventory maka kebutuhan tidak akan terpenuhi. Keberadaan inventory perlu dikelola sedemikian rupa sehingga diperoleh kinerja yang optimal.

Menurut Tumpal Manik (2017:120) Perusahaan dagang mengharakan jumlah persediaan selalu tersedia untuk dijual, maka persediaan barang dagang adalah sejumlah barang dagang yang tersedia didalam perusahan sebelum dijual kepada pelanggan (costumer) dicatat sebagai asset lancar. Ketersediaan persediaan barang dagang merupakan hal yang sangat penting bagi perusahaan dagang.

Toko Obyth merupakan salah satu toko yang bergerak di bidang barang yang menjual berbagai macam alat tulis kantor mulai dari kertas, printer, tinta dan lain

Toko obyth ini beralamat di Jalan Sabirin Muchtar No.17 Kuala Kurun, Kabupaten Gunung Mas, Kota Palangka Raya.

Adapun penjualan barang alat tulis kantor ini memiliki proses yang sangat cepat. Pada toko Obyth data inventory masih dibuat didalam buku agenda besar, sehingga pemilik toko dan kasir akan kesulitan saat melihat informasi data inventory barang yang ada. Kasir tidak dapat melihat jumlah stok banyaknya barang yang tersedia, sehingga saat ada permintaan barang yang masuk lumayan besar kasir harus mencek terlebih dahulu ke gudang apakah stok barang mencukupi atau tidak.

Menurut Zayid Musiafa (2019:3) Reorder Point (pemesanan kembali) adalah seuah nilai dimana suatu prus dilakukan (persiapan dimulai). Hali ini juga dipengaruhi oleh lead time (waktu) yang diperlukan unntuk menerima kuantitas pesanan dikeluarkan atau persiapan dimulai.

Dengan adanya sistem informasi ini persediaan barang dengan menggunakan metode $R e$ order point ini pemilik toko dapat mengecek persediaan jumlah barang tanpa harus pergi kegudang terlebih dahulu, dan menghindari dari kehabisan stock jumlah persediaan barang dan pemilik toko dapat mengetahui titik waktu kapan harus dilakukannya pemesanan kembali.

Tujuan dibangunnya sistem informasi ini diharapkan dapat membantu pihak Toko Obyth dalam proses pengolahan inventory barang untuk mencegah terjadinya stagnation, dan mengurangi masalah informasi.

\section{TINJAUAN PUSTAKA}

\subsection{Inventory (Persediaan)}

Menurut Agus Ristono (2013:2) Inventory adalah suatu teknik yang berkaitan dengan penetapan terhadap besarnya persediaan bahan yang harus diadakan untuk menjamin kelancaran dalam kegiatan operasi produksi, serta menetapkan jadwal pengadaan dan jumlah pemesanan barang yang harus dilakukan oleh perusahaan.

Tujuan pengelolaan inventory menurut Agus Ristono (2013:4) adalah :

1. Untuk dapat memenuhi kebutuhan atau permintaan konsumen dengan cepat ( memuaskan konsumen). 
2. Untuk menjaga kontinuitas atau menjaga agar perusahaan tidak mengalami kehabisan persediaan yang mengakibatkan terhentinya proses produksi. Hal ini dikarenakan alasan :

a) Kemungkinan barang (bahan baku dan penolong) menjadi langka sehingga sulit untuk diperoleh.

b) Kemungkinaan supplier terlambat mengirimkan barang yang dipesan.

3. Untuk mempertahankan dan bila mungkin meningkatkan penjualan dan laba perusahaan.

4. Menjaga agar pembelian secara kecil-kecilan dapat dihindari, karena dapat mengakibatkan ongkos pesan menjadi besar.

5. Menjaga supaya penyimpanan dalam emplacemenet tidak besar-besaran, karena akan mengakibatkan biaya menjadi besar.

Dari beberapa tujuan pengendalian diatas maka dapat disimpulkan bahwa tujuan pengendalian persediaan (inventory) adalah untuk menjamin tedapatnya persediaan sesuai kebutuhan.

\subsection{Reorder Point}

Reorder Point (ROP) adalah suatu tingkat persediaan yang mengharuskan untuk melakukan pemesanan kembali pada persediaan dengan mempertimbangkan waktu tunggu yang akan terjadi ketika saat pemesanan hingga pesanan di terima. Menurut Fahmi (2016: 122) adalah titik dimana suatu perusahaan atau institusi bisnis harus memesan barang atau bahan guna menciptakan kondisi persediaan yang terkendali.

Safety Stock merupakan persediaan tambahan yang diadakan untuk elindungi atau menjaga kemungkinan terjadinya kekurangan bahan atau stock out (Ikhwanina, 2017).

Jay Heizer dan Barry Render (2015: 567) menyatakan bahwa titik pemesanan ulang yaitu tingkat persediaan dimana ketika persediaan telah mencapai tingkat dimana pemesanan harus dilakukan. Analisis reorder point digunakan untuk menganalisis titik pemesanan ulang menurut Heizer dan Render (2015: 567) dapat digunakan rumus sebagai berikut:

Dimana :

\section{Reorder point $=(\mathbf{L T} \times \mathbf{A U})+\mathrm{SS}$}

$\mathrm{AU}=$ permintaan (perhari, perbulan, perminggu atau pertahun)

$\mathrm{LT}=$ waktu tenggang (lead time)

SS = Safety Stock (Persediaan Pengaman)

\subsection{Website}

Menurut Rahmat Hidayat (2010 : 2) Website atau situs diartikan sebagai sekumpulan halaman-halaman yang digunakan untuk menampilkan informasi teks, gambar diam atau gerak, animasi, suara, dan atau gabungan dari semuanya, baik bersifat statis maupun dinamis yang membentuk satu rangkaian bangunan yang saling terkait, yang masing-masing dihubungkan dengan jaringan-jarigan halaman. Hubungan antara satu halaman web dengan halaman web yang lainnya disebut Hyperlink, sedangkan teks yang dijadikan media penghubung disebut dengan Hypertext.

\subsection{Sistem Informasi}

Menurut Elisabet Yunaeti Anggraeni dan Rita Irviani (2017 : 1) sistem adalah sekumpulan orang yang saling bekerja sama dengan ketentuan-ketentuan aturan yang sistematis dan terstruktur untuk membentuk satu kesatuan yang melaksnakan suatu fungsi untuk mencapai tujuan, sistem memiliki beberapa karaktersktik atau sifat yang terdiri dari komponen sistem, batasan sistem, lingkungan luar sistem, penghubung sistem, masukan sistem. Sedangkan 
infirmasi adalah data yang diolah menjadi lebih berguna dan berarti bagi penerimanya, serta mengurangi ketidakpastian dalam proses pengambilan keputusan mengenai suatu keadaan.

Sistem informasi merupakan suatu kombinasi teratur dari orang-orang, hardware, software, jaringan komunikasi dan sumber daya data yang mengumpulkan, mengubah, dan menyebarkan informasi dalam sebuah organisasi.

\section{METODE PENELITIAN}

\subsection{Metode Pengumpulan Data}

Metode pengmpulan data digunakan melakukan analisis kebutuhan Sistem serta alat dan bahan yang dibutuhkan dalam mencapai tujuan penelitian. Metode pengumpulan data yang digunakan dalam penelitian ini yaitu observasi, wawancara, studi pustaka. Dari metode pengumpulan data maka didapatkan beberapa referensi dalam mendukung penelitian.

\subsection{Metode Pengembangan Perangkat Lunak}

Metodologi pengembangan dalam pembuatan sistem informasi menggunakan waterfall system menurut Sommerville (2011: 30).

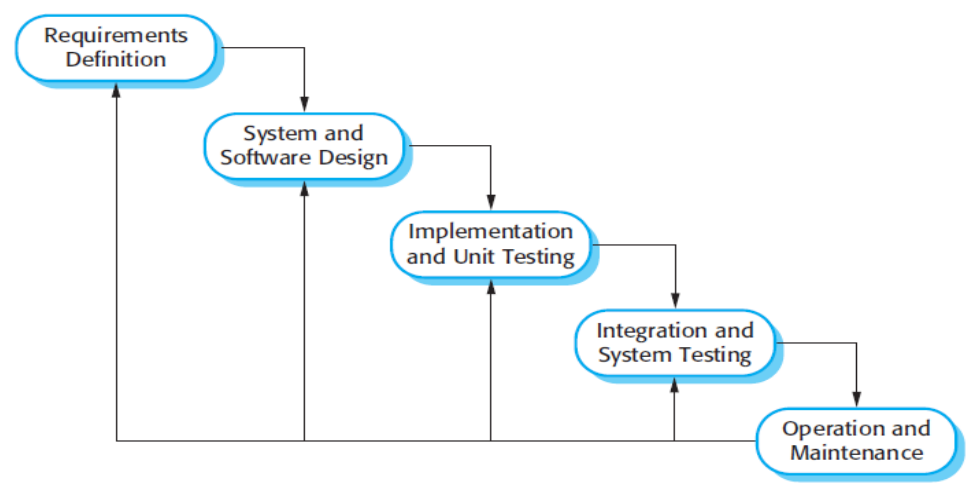

Gambar 1 Diagram Alur Metodologi Waterfall (Sommerville, 2011)

\section{Requirements Definition}

Pada tahap peneliti ini melakukan analisis sistem yang sedang berjalan, melakukan wawancara langsung dengan pemilik toko mengenai permasalahan yang ada dan tujuan perancangan sistem baru, merancang batasan sistem serta kebutuhan yang diperlukan untuk pembuatan sistem. Kemudian peneliti memberikan sistem usulan dari masalah yang ada untuk dibuatkan sistem yang baru. 


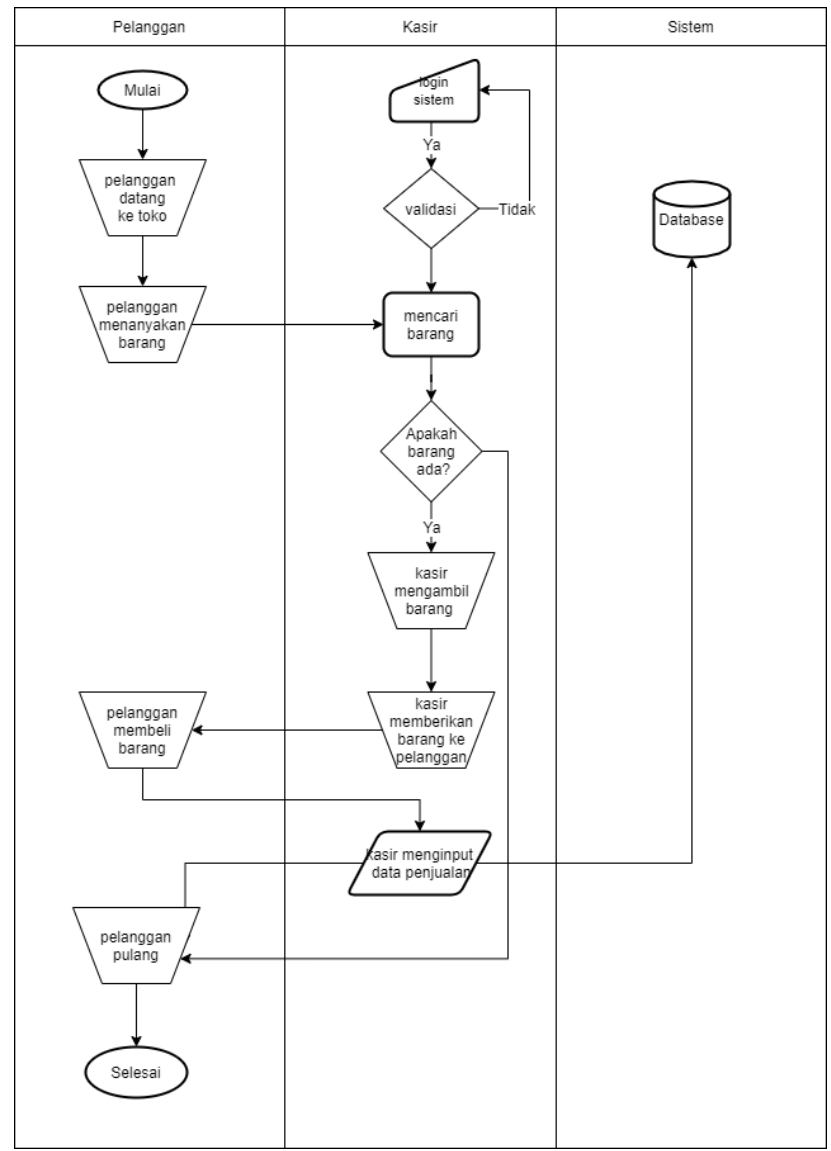

Gambar 2 Flowchart Sistem Baru Penjualan

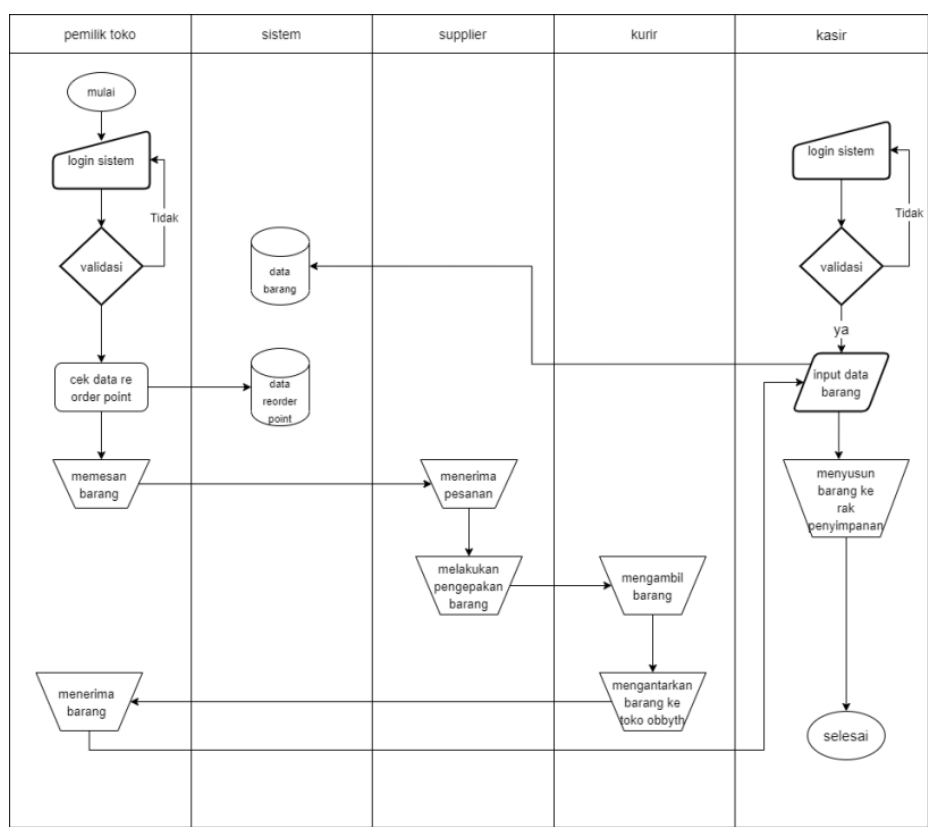

Gambar 3 Flowchart Sistem Baru Pembelian

2. System and Software Design

Dari usulan sistem yang baru, pada tahap ini peneliti melakukan perancangan sistem mulai dari desain sistem menggunakan Data Flow Diagram (DFD) sebagai alat 
pembuatan model dan merancang desain database menggunakan Entity Realtionship Diagram (ERD) yang digunakan untuk menjelaskan relasi antar data dalam basis data.

\section{DFD Diagram Konteks dan DFD Level 1}

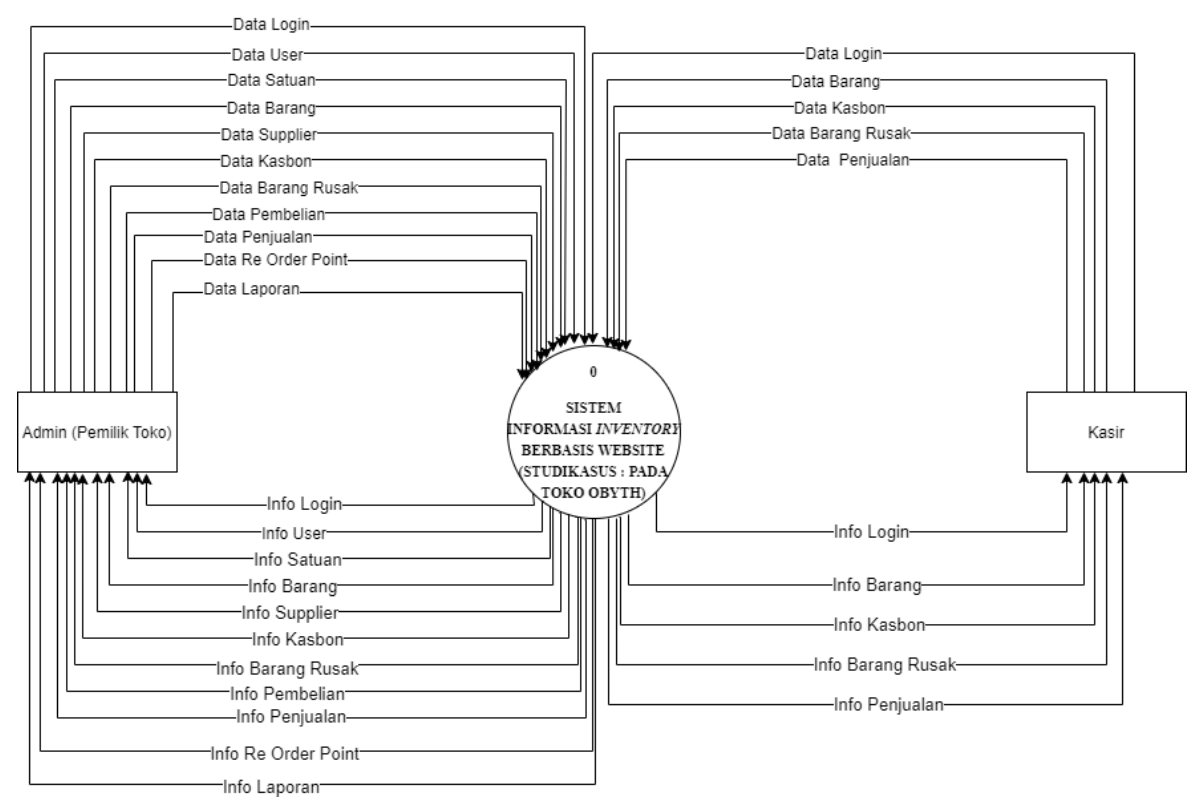

Gambar 4 Diagram Konteks

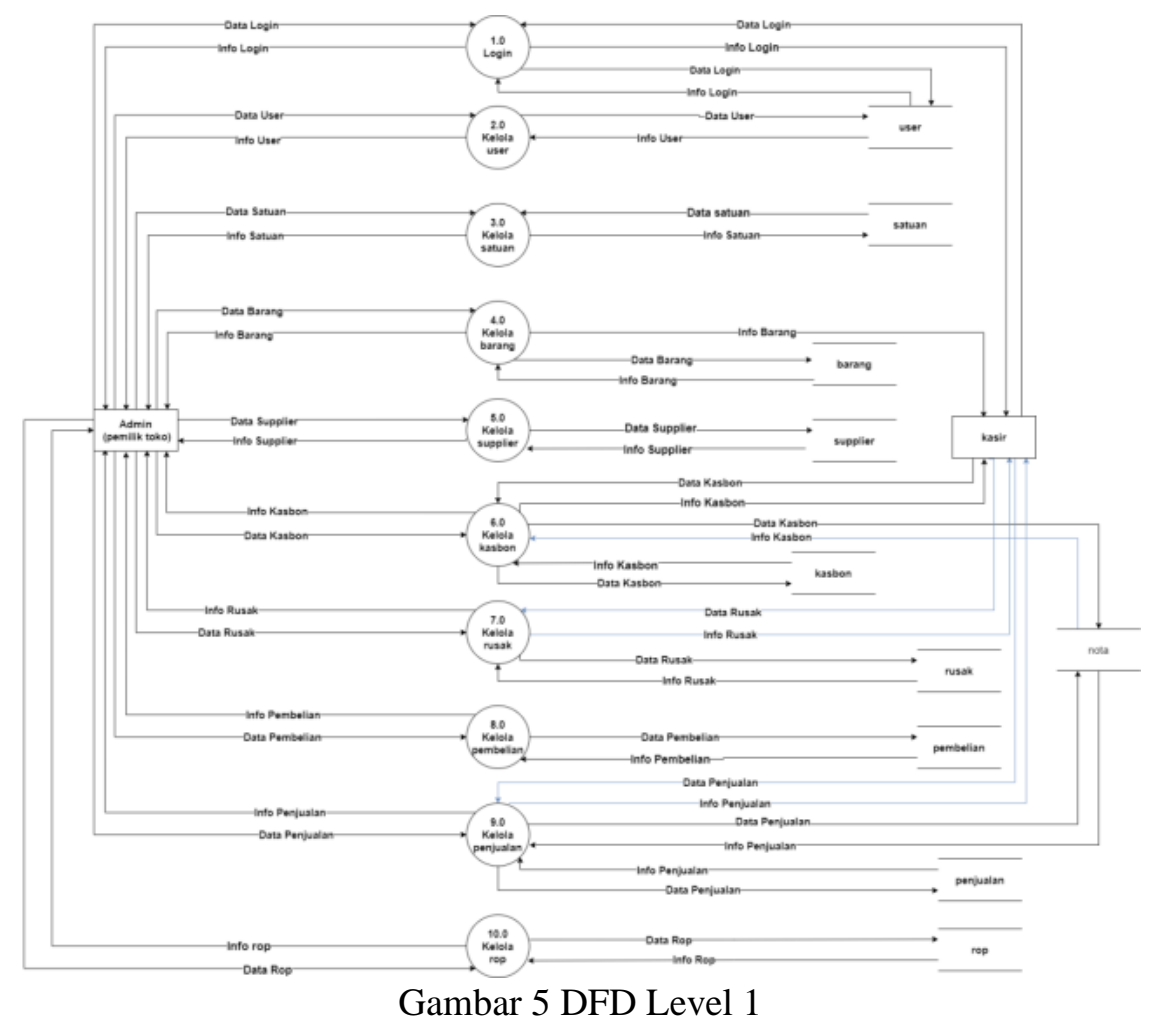




\section{Entity Relationship Diagram}

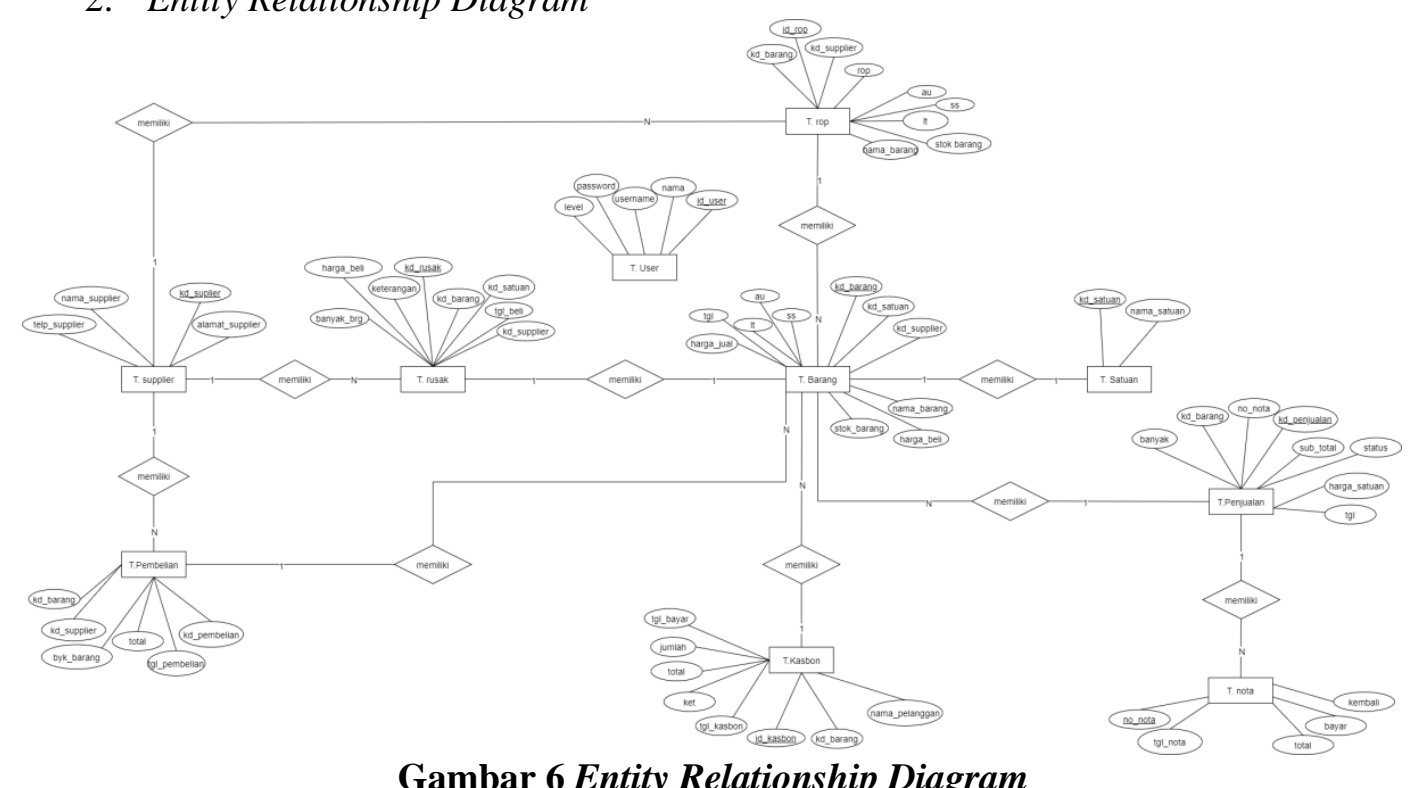

\section{Implementation and Unit Testing}

Pada tahap ini peneliti merealisasikan rancangan sistem pada tahap sebelumnya ke dalam bahasa pemrograman Hypertext Preprocessor (PHP) dan basis data My Structured Query Language (MySQL) menjadi suatu unit program. Kemudian unit program yang telah dibuat tadi dilakukan pengujian untuk mengetahui apakah program sudah berjalan sesuai dengan yang diharapkan peneliti.

4. Integration and System Testing

Setelah pengujian unit program, pada tahap ini peneliti melakukan pengujian kembali terhadap tiap-tiap unit program menjadi satu kesatuan program hingga sesuai dengan yang diharapkan. Peneliti melakukan pengujian menggunakan jenis pengujian black-box. untuk mengetahui apakah fungsi-fungsi, masukan, dan keluaran dari perangkat lunak sesuai dengan spesifikasi yang dibutuhkan.

\section{Operation and Maintenance}

Setelah sistem selesai diuji dan kemudian diberikan ke pengguna sistem (dalam hal ini pengguna sistem adalah pemilik Toko(Admin) dan kasir), pada tahap ini pemilik toko dan kasir mulai mengoperasikan sistem. Sehingga peneliti hanya melakukan hingga tahap Integration and System Testing saja.

\subsection{Metode Re Order Point}

. Metode yang digunakan dalam pembuatan sistem ini yaitu metode Re Order Point. Berikut ini tahapan dari implementasi Re Order Point.

1. Menentukan lead time atau waktu tenggang, biasa nya lead time telah ditentukan oleh pihak yang bersangkutan.

1 hari waktu pengemasan +1 hari waktu barang dalam perjalanan $=2$ hari

2. Menentukan avarage usage rata-rata pemakaian barang (Perbulan)

Rata-rata banyak penjualan + rata-rata banyak kasbon $=26$ box

3. Menentukan safety stock (untuk mengantisipasi tingginya fluktuasi permintaan prodo, Toko Obyth menyediakan persdiaan pengaman (safety Stock) untuk tiap produk sebanyak 50\% dari selisih nilai rata-rata barang yang masuk (pembelian) dan barang keluar (penjualan dan kasbon) pada periode tertentu.

Kertas FC Sidu F4 70Gsm

Supplier : Bintang Timur 


\section{Diketahui :}

Lead Time $=2$ hari

Avarage Usage $=26$ box

Perhitungan Safety Stock:

Safety Stock $=($ Avarage Usage $*$ Lead Time $) 50 \%$

$$
\begin{aligned}
& =(26 \text { box } * 2) 50 \% \\
\text { Safety Stock } & =26 \text { box }
\end{aligned}
$$

4. Menghitung rumus Re Order Point

Perhitungan Reorder Point :

$$
\begin{aligned}
\text { Reorder Point } & =(\mathrm{AU} * \mathrm{LT})+\mathrm{SS} \\
& =(26 \text { box } * 2)+26 \text { box } \\
& =(52 \text { box })+26 \text { box } \\
\text { ROP } & =78 \text { box }
\end{aligned}
$$

\section{PEMBAHASAN}

Setelah desain sistem dan perangkat lunak selesai dibuat, desain direalisasikan ke dalam bahasa pemrograman PHP, kemudian dilakukan pengujian terhadap website yang dibuat dengan tujuan untuk memastikan bahwa setiap fitur dapat berfungsi dengan baik dan sesuai dengan kebutuhan pengguna.

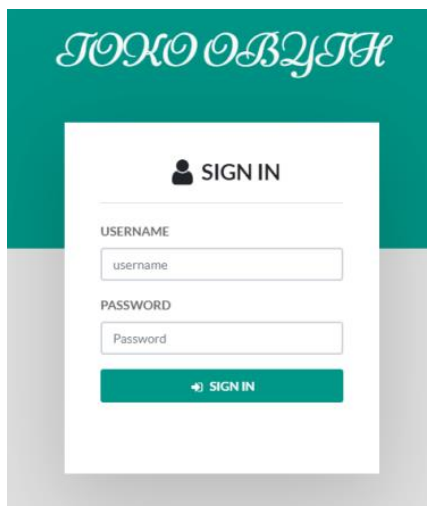

Gambar 7 Halaman Login

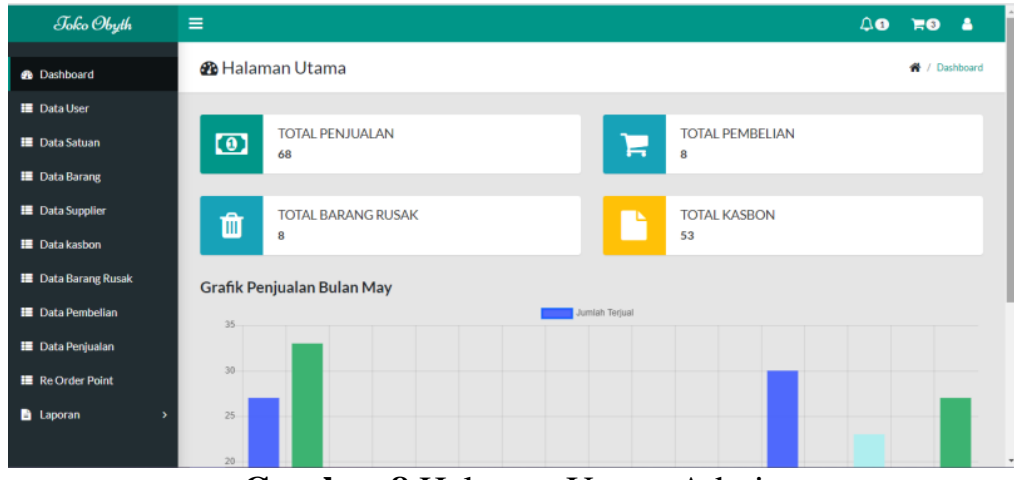

Gambar 8 Halaman Utama Admin 


\section{KESIMPULAN}

Kesimpulan dari penelitian yang telah dilaksanakan adalah sistem ini dirancang dengan menggunakan 2 metode yaitu metode waterfall sebagai metode pengembangan perangkat lunak dan metode Re Order Point sebagai metode dalam sistem informasi inventory yang dibuat.

Kemudian perhitungan pemesanan kembali atau yang disebut juga dengan re order point memiliki 3 faktor untuk mendapatkan hasil dari re order point nya, yaitu dengna menentuka lead time atau jumlah waktu yang dibutuhkan untuk barang tersebut sampai, average usage atau penggunaan rata-rata barang dalam kurun waktu tertentu, dan safety stock adalah persediaan pengaman disgudang untuk mengantisipasi kehabisan stok.

Website ini telah diuji dengan pengujian blackbox yang mengasilkan bahwa fitur dalam website dapat berjalan dengan baik. Sistem Informasi Inventory Berbasis Website (Studi Kasus : Toko Obyth) ini dibangun untuk memberikan informasi persediaan (Inventory) barang yang disimpan untuk dijual.Jumlah data barang pada sistem ini sebanyak 77 data barang, 68 total penjualan pada bulan juni, 8 total barang rusak pada bulan juni, 53 kasbon pada bulan april , 9 total pembelian pada bulan april, dan terdapat 77 data pada re order point. Terdapat 7 supplier yang menyuplai barang ke Toko Obyth. Terdapat 7 supplier yang menyuplai barang ke Toko Obyth, dan terdapat 4 menu laporan yang dapat dikelola dan dapat diprint, laporannya antara lain yaitu : laporan data barang, laporan penjualan, laporan pembelian, dan laporan barang rusak. Untuk data Re Order Point jumlah barang yang tersedia masih aman dan belum bisa dilakukan pemesanan ulang karena stok barang masih melampaui safety stock.

\section{DAFTAR PUSTAKA}

[1] Abdurahman, Muhdar. 2017. Sistem Informasi Pengolahan Data Pembelian Dan Penjualan Pada Toko Koloncucu Ternate. Politeknik Sains dan Teknologi Wiratama Maluku Utara : Maluku Utara.

[2] Anggraeni, Elisabet Yunaeti \& Rita Irviani. 2017. Pengantar Sistem Informasi. Penerbit Andi : Yogyakarta.

[3] Arief, M. R. 2011. Pemrograman Web Dinamis Menggunakan PHP dan MySQL. Andi : Yogyakarta.

[4] Hidayat, Rahmat. 2010. Cara Praktis Membangun Website Gratis. PT Elex Media Komputindo Kompas - Gramedia : Jakarta.

[5] Heizer, Jay dan Barry Render. 2015. Manajemen Operasi Edisi 11. Salemba Empat : Jakarta 